\title{
GvHD Final Lung Score
}

National Cancer Institute

\section{Source}

National Cancer Institute. GvHD Final Lung Score. NCI Thesaurus. Code C131043.

A scoring system for graft versus host disease that combines a symptoms score with a score for FEV1. 